\title{
Note from the Editor
}

This issue offers two interpretive essays and a case study on disparate matters: sexuality, southern educational reform, and Wilsonian diplomacy. In their ways, the essays recall themes that have recurred in historical writing on the Progressive Era for the last fifty years: the limits of knowledge, even about a period so close and so literate; discomfort with the moralistic and improving side of progressivism; and the continuing relevance of progressivism because its hopes and anxieties endure within American culture and politics.

In the course of summing up forty years of scholarship on sexual lives, sexuality, and sexual reform, Catherine Cocks notes that many aspects of this feature of people's everyday experience will remain unknown forever. By implication, Cocks comments on the limits of the social history agenda undertaken with such enthusiasm two generations ago. She also by implication comments on how shifts in present-day culture and discourse affect the historical enterprise. Early practitioners of the history of sexuality for the most part accepted that the "sexual liberalism" discussed by Cocks was irreversible and good. The past forty years have seen much disillusion with the possibilities and likely benefits of an expansive sexual liberalism. This disillusion has affected the narrative and interpretation of the history of sexuality in ways that would certainly have surprised scholars present at the outset of this enterprise.

Some historical questions remain unresolved not for lack of evidence, but because they rest on counterfactuals. Lloyd Ambrosius revisits one of the major "what ifs" of the twentieth century: Wilsonian internationalism. Because the reality of international affairs in the 1930s and 1940s was so horrific, historians have understandably and frequently looked at Woodrow Wilson's agenda for the League of Nations with retrospective hope. Ambrosius suggests that given the inherent contradiction in Wilson's vision between multilaterialism and unilateralism, Wilson may not have been offering a more workable solution than his critics to the disarray of Europe and Asia the end of World War I. Much of the continuing relevance of Wilsonian internationalism, Ambrosius suggests further, stems from its disturbing qualities, such as its triumphalist and aggressive presumptions regarding democracy, progress, and the American mission. Careful readers will note that Wilson, the Ph.D. president, repeatedly attributes Jefferson's terms, "entangling alliances," to George Washington, whose Farewell Address warned against "permanent alliances." 
Louise Anderson Allen, meanwhile, offers a case study on a major subject that carries the potential for much further study: the influence of Deweyan ideas on the day-to-day operations of schools in different regions of the United States. Especially given the cliches and misunderstandings that have attached themselves like barnacles to the historical reputation of Deweyan reform, Dr. Allen performs a service in asking what progressive education in fact meant in two schools in the South. Surely opportunities exist for more research into the practical influence of progressive education, and this journal will gladly consider manuscripts on the topic.

Alan Lessoff 